\title{
SOME OBSERVATIONS ON SMALL FATIGUE CRACKS IN A SUPERALLOY
}

\author{
G. P. SHELDON* \\ Olin Metals, New Haven, CT, U.S.A. \\ T. S. COOK* \\ General Electric, Cincinnati, OH, U.S.A. \\ J. W. JONES + \\ The University of Michigan, Ann Arbor, MI, U.S.A. \\ and \\ J. LANKFORD \\ Southwest Research Institute, San Antonio, TX, U.S.A \\ (Received in final form 15 October 1980)
}

\begin{abstract}
An investigation into the applicability of linear elastic fracture mechanics to very small fatigue cracks growing in a powder metallurgy nickel base superalloy is described. An unusual specimen was designed to facilitate the study of these small cracks. The stress intensity factor for the specimen was estimated and then calculated from the plastic zone size as determined by interferometry. The crack tip deformation field was also observed in the SEM and by stereoscopic viewing. These observations showed that the macroscopic deformation field was the same for both the long and short cracks, and was controlled by the stress intensity. The fatigue crack tip was found to interact strongly with the material microstructure and the local growth rate cannot be correlated with fracture mechanics quantities.
\end{abstract}

$B \quad$ Thickness

E Elastic modulus

$K \quad$ Stress intensity factor

$K_{\max } \quad$ Maximum stress intensity factor

$K_{\min } \quad$ Minimum stress intensity factor

$K_{\text {th }} \quad$ Threshold stress intensity factor

$\Delta K \quad$ Stress intensity factor range

$P \quad$ Applied load

\section{Nomenclature}

$R \quad$ Applied load ratio

$W \quad$ Width

a Crack length

$r_{y} \quad$ Plastic zone height

$\alpha \quad$ Geometry correction factor

$\beta \quad$ Constant

$\sigma \quad$ Applied stress

$\sigma_{y} \quad$ Yield stress

\section{INTRODUCTION}

THE QUESTION of the applicability of linear elastic fracture mechanics (LEFM) to very small cracks has been raised by a number of authors [1-5]. This question is of theoretical interest but, more importantly, it is a practical concern when life prediction of gas turbine engines is attempted. High performance engines contain very highly loaded structures, e.g., the first

\footnotetext{
- Formerly Southwest Research Institute

† Formerly Air Force Materials Laboratory, Wright-Patterson AFB, Ohio.
} 
stage turbine disk. The critical crack size in such a disk made of an advanced nickel-base superalloy is small enough that design life is often initiation life, i.e., the number of cycles required to grow a $0.8 \mathrm{~mm}$ crack. In order to utilize LEFM confidently in such an application, it is necessary to know how cracks in the length range $0.1-0.8 \mathrm{~mm}$ behave. This paper describes some initial work undertaken in a program to make such a determination.

\section{EXPERIMENTAL PROGRAM}

The material selected for use in this study was Gatorized ${ }^{\text {(x) }} \mathrm{IN}-100$, a nickel-base superalloy formed by a powder metallurgy (PM) process, and characterized by a very fine grained (3-7 $\mu \mathrm{m})$, homogeneous microstructure. Typical chemical composition is $0 \cdot 07 \mathrm{C}$, $12.4 \mathrm{Cr}, 18 \cdot 5 \mathrm{Co}, 3 \cdot 2 \mathrm{Mo}, 4.32 \mathrm{Ti}, 4.98 \mathrm{Al}, 0.78 \mathrm{~V}, 0.02 \mathrm{~B}, 0.067 \mathrm{Zr}$, balance $\mathrm{Ni}$. Nominal room temperature properties are $\sigma_{y}=1082.5 \mathrm{MPa}$ and $E=213.8 \mathrm{GPa}$. This material was chosen as being representative of current disk materials and also because of its very homogeneous structure. It was felt that the lack of inclusions, carbides, and other complicating microstructural features made this an ideal model material.

The specimen used in this program was designed especially to facilitate study of the propagation of very small cracks. A $19.0 \mathrm{~mm}$ wide, single edge notch specimen containing a notch of length $5.33 \mathrm{~mm}$ was cycled at $5 \mathrm{~Hz}, R=0.05$, to produce a fatigue crack approximately $2 \mathrm{~mm}$ long. The initial stress intensity range was about $\Delta K=22 \mathrm{MPa} \sqrt{\mathrm{m}}$; as the crack grew, the load was gradually reduced until the approximate room temperature threshold for $\mathrm{IN}-100, K_{\mathrm{th}}=8.8 \mathrm{MPa} \sqrt{\mathrm{m}}$ was reached. The specimen was then machined and polished into the configuration shown in Fig. 1 using a two step process. First, the approximate configuration was obtained by electrodischarge machining; then the remainder of the material was removed using progressively finer polishes down to a final polish of $0.05 \mu \mathrm{m}$ alumina. Cracks as short as $0.06 \mathrm{~mm}$ were produced in this fashion.

As shown in Fig. 1, the cross section of the specimen was a parallelogram and contained a crack at one of the acute corners. This configuration was chosen for two reasons. First, the taper allows a better definition of the crack front location. Second, a very short through thickness crack would interact with a great number of grains along its crack front and, because of its very short length, would not really be representative of a naturally occurring crack. The crack in the taper, on the other hand, interacts with a much smaller

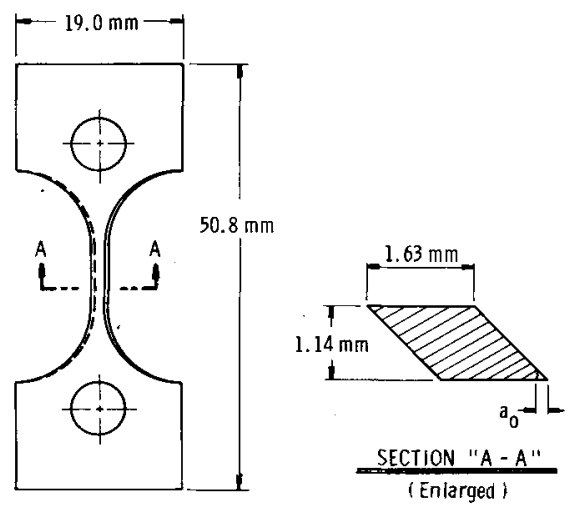

Fig. 1. Specimen geometry for small flaw fatigue tests. 
amount of material along its crack front and is somewhat more representative of a natural small crack.

\section{STRESS INTENSITY FACTOR DETERMINATION}

The unusual geometry of this specimen makes the exact computation of the crack tip stress intensity factor difficult. In this case, a simple estimation procedure was used to determine the stress intensity. First it was assumed that the flaw could be represented as a constant radius crack in a $45^{\circ}$ wedge. Then, following Liu [6], symmetry arguments based on surface flaws and free surface corrections were used to arrive at a value of

$$
K=0.82 \sigma \sqrt{\pi a} .
$$

The same estimation procedure was used to determine the stress intensity for a half penny surface flaw. The latter result was within $2 \%$ of Tracey's finite element value obtained using three dimensional singularity elements [7]; this gave confidence that equation (1) provided a reasonable estimate for the geometry of Fig. 1. However, because of the non-uniform gage section, there existed an added stress concentration which we estimated to be $7 \%$.

In general, the extent of plastic deformation surrounding a propagating fatigue crack can be expressed in terms of the maximum applied stress intensity and the material yield strength as:

$$
r_{y}=\beta\left(\frac{K_{\max }}{\sigma_{y}}\right)^{2}
$$

where $\beta$ is assumed to depend only on the material. In this discussion $r_{y}$ is the height of the plastic zone as shown in Fig. 2. It is possible to experimentally determine $K_{\max }$ as a function of crack length and applied stress simply by the determination of the constant $\beta$ and the measurement of the plastic zone height $r_{y}$. For the small crack in the specimen configuration shown in Fig. 1, the stress intensity factor can be generally expressed as:

$$
K=\alpha \sigma \sqrt{\pi a}
$$

where $\alpha$ is a geometric correction factor which may depend on crack length. Substitution of equation ( 3 ) into equation (2) yields:

$$
r_{y}=\beta\left(\frac{\alpha \sigma}{\sigma_{y}}\right)^{2} \pi a .
$$

For constant load and $\alpha$ independent of crack length, equation (4) indicates that the width of the plastic zone varies linearly with crack length. Determination of $\beta$ requires the measurement of $r_{y}$ in a specimen for which the stress intensity calibration is known.

In order to check the stress intensity relationship for the specimen configuration in question, $r_{y}$ was determined by measuring the residual out-of-plane displacements along the crack line at the specimen surface in a manner similar to that of Marci et al. [8]. A specimen containing $0.56 \mathrm{~mm}$ crack was examined using a Zeiss Interference Microscope with thallium illumination. The interference fringe density obtained with the nominally flat specimen surface was increased by introducing an appropriate tilt angle between the specimen and the optical axis of the microscope. In a method similar to that for interferometrically determining the width and depth of a groove in a flat surface, the residual deformation field surrounding the crack was determined. The resulting fringe 


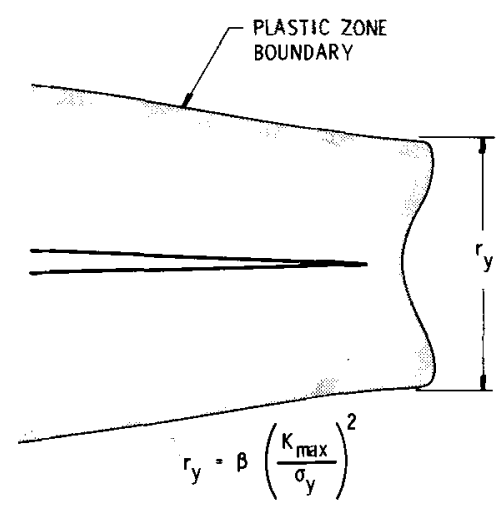

Fig. 2. Geometry of crack tip plastic zone.

pattern and the residual deformation field deduced are shown in Fig. 3. The height of the residual deformation field was assumed to be equivalent to the surface plastic zone height and, as expected from equation (4), was found to vary linearly with crack length as:

$$
r_{y}=0.020+0 \cdot 710 a
$$

where the dimensions are millimeters. The finite zone width at zero crack length resulted from the method of obtaining specimens with small initial flaws as described above. The maximum zone width measured, $0.418 \mathrm{~mm}$, is slightly larger than the predicted [9] plane stress value, $0.297 \mathrm{~mm}$.

Similar measurements were made on a modified compact tension specimen of IN-100. For this specimen geometry [10]:

$$
K=\frac{P \sqrt{a} Y}{B W}
$$

where: $\quad Y=30.96-195 \cdot 8(a / W)+730 \cdot 6(a / W)^{2}-1186 \cdot 3(a / W)^{3}+754 \cdot 6(a / W)^{4} \quad$ and $B=12.7 \mathrm{~mm}$ and $W=63.5 \mathrm{~mm}$ are the specimen thickness and width, respectively; $P$ is the applied load. A fatigue crack was grown at a constant $K_{\max }$ of $38.5 \mathrm{MPa} \sqrt{\mathrm{m}}$ by load shedding with $K_{\min } / K_{\max }=0 \cdot 1$. This produced a plastic zone height of $0.71 \mathrm{~mm}$ which was independent of crack length. Substituting into equation (2) yields

$$
\beta=0.56 \text {. }
$$

The determination of $\alpha$ is made by substitution of equations (5) and (7) into equation (4). For the applied stress of $806.0 \mathrm{MPa}$ under which the small crack was grown,

$$
\alpha=0.80
$$

which gives very good agreement with equation (1).

The value of $\beta$ was subsequently checked in a second specimen, i.e. one of the precracked single edge notched specimens before it was machined into the small flaw specimen. At a $K_{\max }$ of $9.6 \mathrm{MPa} \sqrt{\mathrm{m}}$, the measured height of the plastic zone was $0.04 \mathrm{~mm}$. Using equation (2) we obtain

$$
\beta=0 \cdot 52
$$




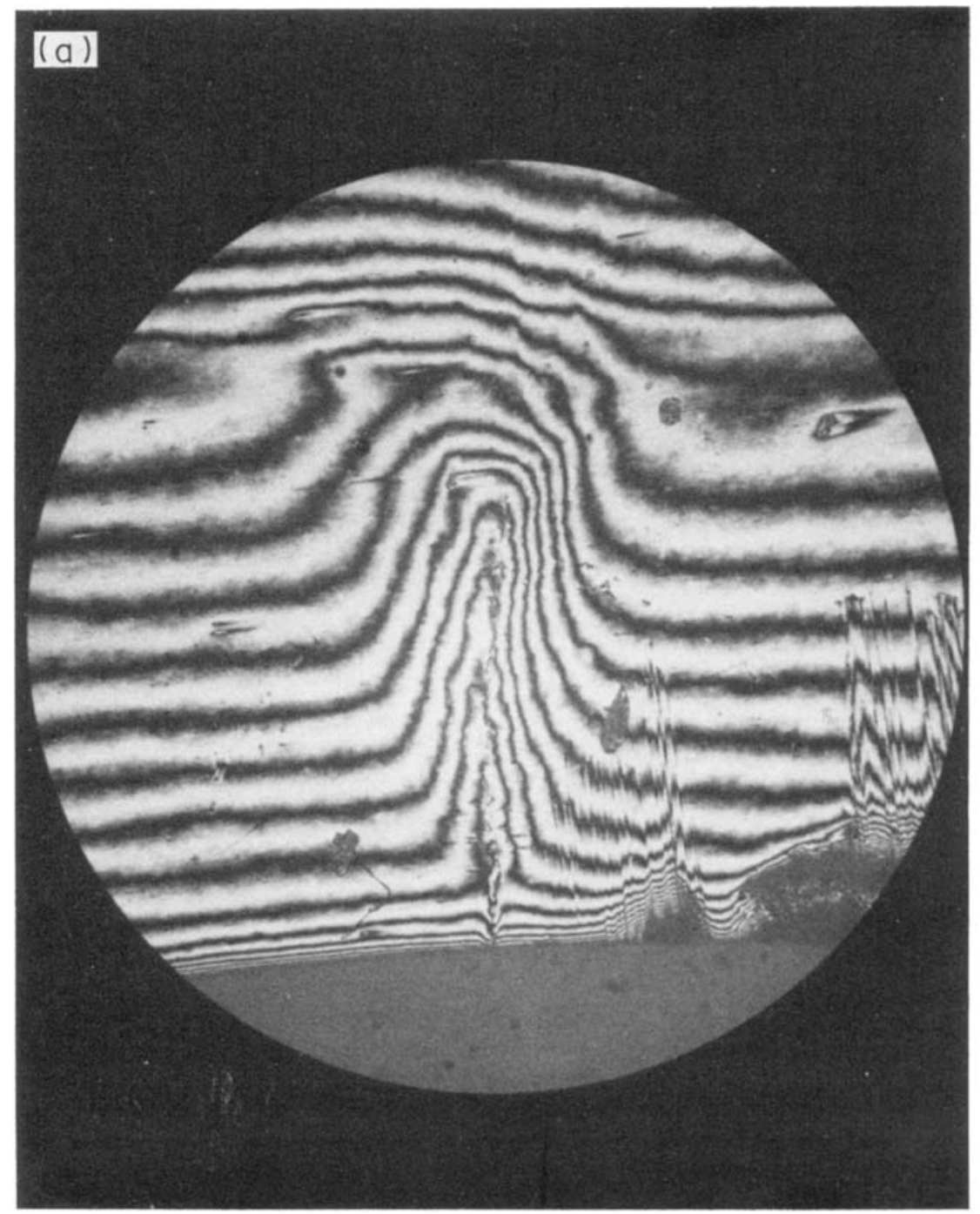

(b)

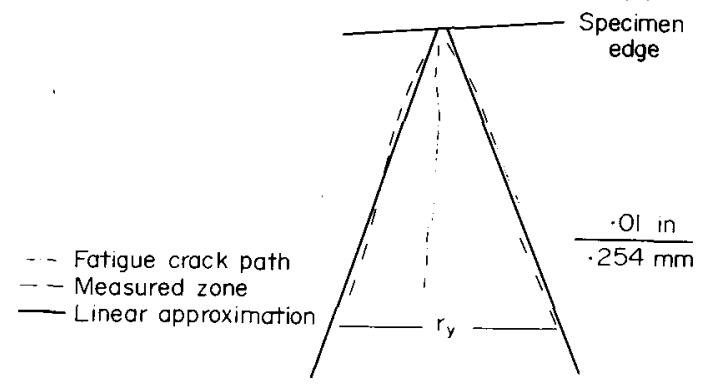

Fig. 3. A $0.56 \mathrm{~mm}$ crack in IN-100 ( $\times 98)$. (a) Interference micrograph. (b) Deformation field carefull traced from Fig. 3a to indicate approximations made. 
The latter figure was obtained by means of a multi-beam interference attachment for a standard metallurgical microscope. The fact that the result was obtained with a different interferometric setup and specimen design, yet agrees so well with equation (7), serves to give additional confidence in the value.

\section{DISCUSSION}

In utilizing this technique to obtain the stress intensity factor, we have assumed that the extent of the plastic zone for this material is given by equation (2) and that this general relationship applies regardless of the specimen configuration. The shape of the plastic zone is dependent on the material [9] but should not vary for the same material. While we were unable to devise a technique to measure the extent of the plastic zone ahead of the crack to confirm this, the general features of crack growth indicated similarities between different specimens. Figure 4 compares the crack tip in the small flaw specimen (Fig. 1), $a=0.28 \mathrm{~mm}$, with a precrack specimen, $a=7.39 \mathrm{~mm}$. The extent of the crack tipmicrostructure interaction is evident in the nonplanar crack path. Both crack tips exhibit the transgranular, highly crystallographic crack growth often observed in nickel-base superalloys [11]. However, the fine grain microstructure prevents the planar fracture from extending any great distance and results in a very tortuous crack path. The crack does, on average, retain the macroscopic Mode I growth pattern, however, even for the small crack lengths. While not shown, the appearance of the crack in the compact tension specimen appeared exactly like the tips depicted in Fig. 4.

Although we were unable to define the limits of the plastic zone, we have recently developed a new technique for mapping out the deformation field very near a crack tip, which further supports the idea that the long and short crack tips behave similarly, at least on the surface where the observations were made. This approach, described in detail elsewhere [12], is based on the well-known phenomenon of stereoscopic viewing, whereby pictures of a region photographed at different tilts are viewed simultaneously in a stereo viewer, so that surface relief is created. We have found that artificial surface relief, which in essence maps out the height of the plastic zone, is created by viewing loaded and unloaded SEM photomicrographs of a given crack tip, just as in the interferometric technique. Further, the topography observed relates to the actual details of the shearing and rotation which accompany fatigue crack tip yielding. In applying this technique to long and short cracks in IN-100, we have found that surface crack tip opening modes and the attendant plastic yielding are virtually identical for long and short cracks.

This similarity of deformation observed in the specimens with both large and small cracks gives confidence that the response of the material to the crack tip driving force is macroscopically the same for both large and small cracks. While there are considerable differences in the local slip character at the crack tip, these effects are due to the difference in load and not crack size per se. This is demonstrated by our real time observations of the cracks growing in an SEM fatigue stage which show that both the long and the short cracks interact strongly with the grain boundaries [13], and in fact are held up by the boundaries. The crack tips are delayed at the grain boundaries until the cyclic crack opening displacement generates sufficient slip in the next grain that the crack tip can proceed across the boundary. The crack advances rapidly after the barrier has been breached but it slows as the crack tip approaches the next boundary. The crack halts and then repeats the slip generation process. At low loads this is expected since for a $0.08 \mathrm{~mm}$ crack cycled slightly 


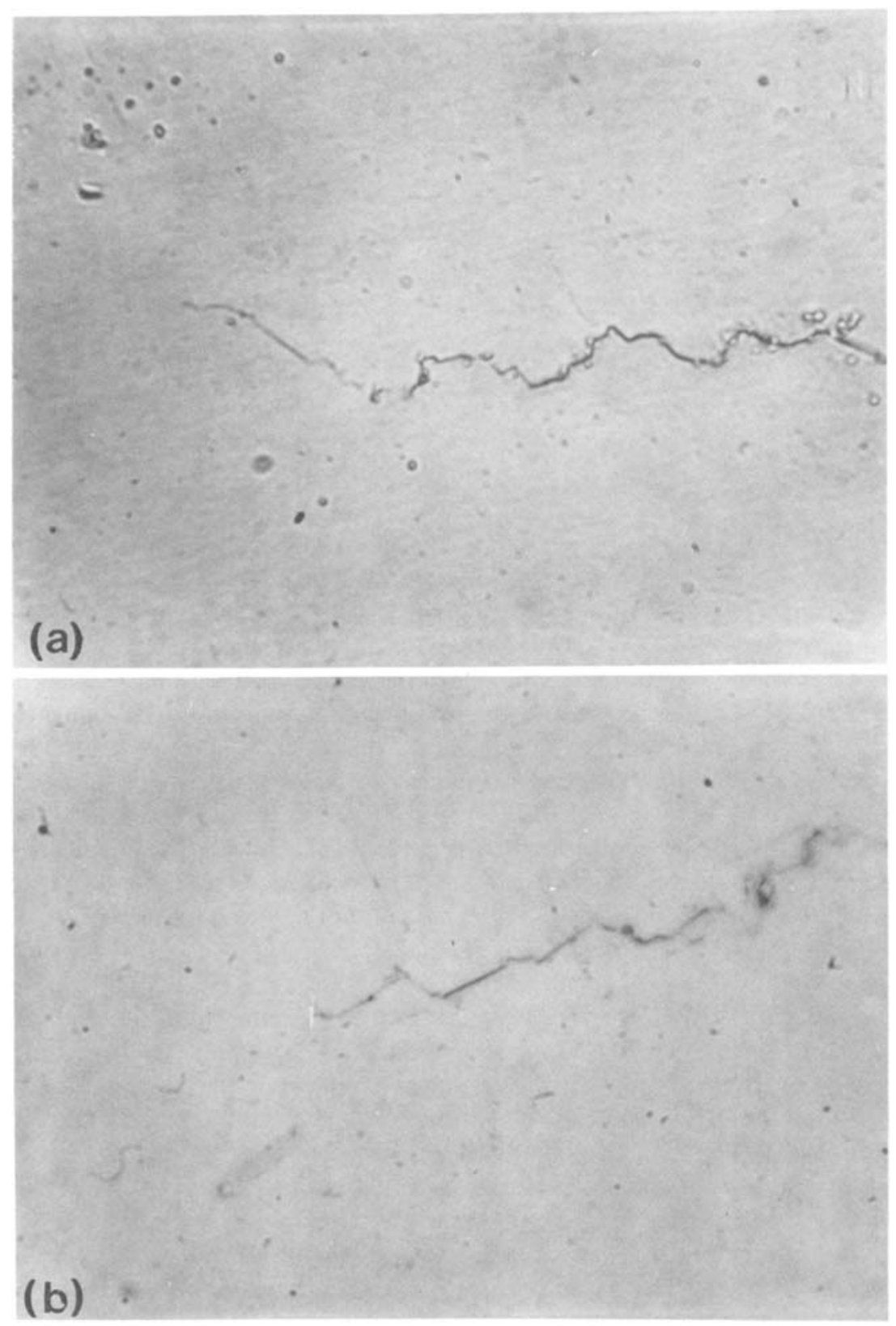

Fig. 4. Fatigue crack tip morphology. (a) after 200000 cycles, crack length of $0.28 \mathrm{~mm}(\times 1600)$. (b) in single edge notch specimen, crack length of $7.39 \mathrm{~mm}(\times 1600)$.

above threshold, the cyclic plastic zone is about equal to the grain size; hence the orientation of the individual grains ahead of the crack is crucial to the slip generation and crack advance process. This is dramatically demonstrated in Fig. 5 which shows a crack being held for 4000 cycles by a pair of unfavorably oriented grains. The persistence of this crack tip-grain boundary interaction at higher load levels is somewhat surprising, however. 


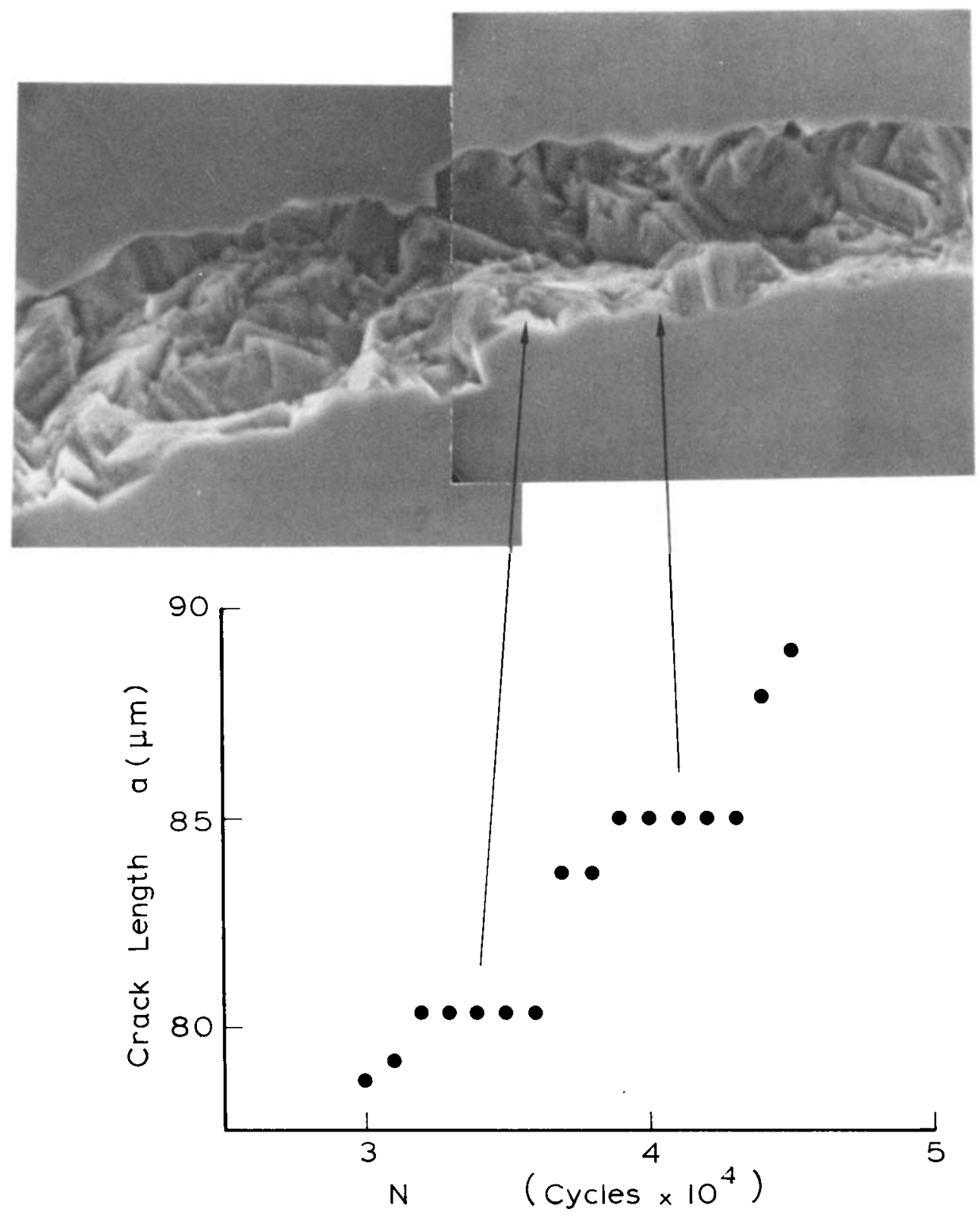

Fig. 5. Correspondence between fracture surface and crack growth pattern.

Considerable delays were observed for the relatively long crack length of $0.38 \mathrm{~mm}$ $(\Delta K=24.5 \mathrm{MPa} \sqrt{\mathrm{m}})$ when the crack tip encountered a grain boundary. Since the cyclic plastic zone size is a little less than an order of magnitude larger than the grain size under these conditions, it was expected that the grain boundary delays would not be observed. Of course, unless incremental crack growth measurements are made on a scale comparable to those used in these experiments, the delays and subsequent accelerations involved in grain 
boundary crossing are averaged out. In other words, the macroscopic deformation field of either large or small cracks may be explained in terms of fracture mechanics concepts; however, when the details of the crack advance process are examined on a scale comparable to the microstructure and the small crack, the rate of advance will not correlate with the stress intensity.

It is crucial to remember that these are surface observations only. Because the crack tip interacts with a large number of grains along its front, subsurface grains oriented unfavorably will also hinder crack advance. For the small flaw, only a few obstacles will be needed to pin the crack for a large number of cycles. (Recall the 4000 cycle delays in Fig. 5). As the crack grows, the longer crack front is delayed less; the blockages are less effective because of the increased $\Delta K$ and the increased line tension along the crack front.

\section{CONCLUSIONS}

The results described herein have indicated that under certain conditions it is possible to predict the cyclic stress history that a crack has experienced simply by measuring the residual deformation associated with the crack propagation. Recent work by Uchimoto et al. [14] supports this conclusion. In their work the width of the deformation zone was determined by X-ray line broadening analysis and involved the incremental removal of material normal to the fracture surface. While the interferometric technique depends on having a relatively flat and polished surface, it should be quite useful in the laboratory as a check for $K$ solutions in crack growth specimens of complex geometry where the maximum stress and the stress ratio were well defined. It should also be noted that the interferometric technique determines the deformation at the specimen surface where plane stress conditions are assumed to exist. This should reduce the scatter from specimens of varying thickness in which conditions in the specimen interior may differ from plane stress, since the stress state of the specimen surface should be independent of thickness.

The observations of the fatigue crack behavior in the IN-100 PM material serve to confirm the assumptions underlying this technique. The detailed study of the crack tip shows that the deformation field created by the fatigue crack is the same for both large and small cracks. That is, macroscopic deformation is controlled by the stress intensity, i.e. fracture mechanics, and not by the crack size alone. Locally, however, the crack tip interacts strongly with the grain boundaries and thus the local crack growth rate cannot be correlated with fracture mechanics quantities. These effects are most noticeable with small flaws since the observations are made, of necessity, at low $\Delta K$ values if LEFM is to be applicable. For larger cracks at higher stress intensities, the interactions persist, but for shorter times. Moreover, the increased size samples a greater volume of material and is therefore less affected by individual grain orientations along the subsurface crack front. The details of the effects of the crack size on the growth rate are discussed in a companion paper [15] describing the results of the fatigue crack growth experiments conducted during this program.

Acknowledgement - The research described in this paper was sponsored by the Air Force Materials Laboratory under Contract No. F33615-76-C-5242. The support of the Project Monitor, Dr. W. H. Reimann, is greatly appreciated. J. W. Jones wishes to express his appreciation to the National Research Council and the Air Force Materials Laboratory for support during a portion of this research. Support was also received from a Southwest Research Institute Internal Research Grant. 


\section{REFERENCES}

[1] Smith, R. A. (1977) On the short crack limitations of fracture mechanics. Int. J. Fract. 13, $717-720$.

[2] Talug, A. and Reifsnider, K. (1977) Analysis and investigation of small flaws, cyclic stress-strain and plastic deformation aspects of fatigue crack growth. ASTM STP 637, 81-96.

[3] El Haddad, M. H., Smith, K. N. and Topper, T. H. (1979) Fatigue propagation of short cracks. $J$. Engng Mater. Tech., Trans. ASME 101, 42-46.

[4] Tanaka, K., Nakai, Y. and Yamashita, M. Fatigue growth threshold of small cracks. Int. J. Fract. (Submitted).

[5] Kitagawa, H. and Takahashi, S. (1976) Applicability of fracture mechanics to very small cracks or the cracks in the early stages. Proceedings of the Second International Conference on Mechanical Behavior of Materials, Boston, 627-631.

[6] Liu, A. F. (1972) Stress intensity factor for a corner flaw. Engng. Fract. Mech. 4, 175-179.

[7] Tracey, D. M. (1973) 3-D elastic singularity element for evaluation of $\mathrm{K}$ along an arbitrary crack front. Int. J. Fract. 9, 340-343.

[8] Marci, G., Packman, P. F. and Jones, J. W. (1976) The direct measurement of plastic zones associated with propagating fatigue cracks. Proceedings of the Second International Conference on Mechanical Behavior of Materials, Boston, 583-589.

[9] Lankford, J., Davidson, D. L. and Cook, T. S. (1977) Fatigue crack tip plasticity, cyclic stress-strain and plastic deformation aspects of fatigue crack growth. ASTM STP 637, 36-55.

[10] Imhof, E. J. and Barsom, J. M. (1973) Fatigue and corrosion-fatigue crack growth of 4340 steel at various yield strengths, progress in flaw growth and fracture toughness. ASTM STP 536, $182-205$.

[11] Gell, M. and Leverant, G. R. (1973) Mechanisms of high temperature fatigue, fatigue at elevated temperatures. ASTM STP 520, 37-67.

[12] Davidson, D. L. (1979) Fatigue crack tip displacement observations. J. Mater. Sci. 14, 231-233.

[13] Cook, T. S., Lankford, J. and Sheldon, G. P. (1978) Research on growth of microcracks in nickel-base superalloys, AFML-TR-78-133.

[14] Uchimoto, T. et al., (1977) Qualitative evaluation of electronfractography of fatigue fracture surface. Trans Iron Steel Inst. Japan. 17, 1-10.

[15] Lankford, J., Cook, T. S. and Sheldon, G. P. Fatigue microcrack growth in a nickel-base superalloy. Int. J. Fract. (in press). 